\title{
PENGARUH MAGNETASI BAHAN BAKAR TERHADAP PERFORMANSI MOBIL DIESEL PRODUKSI TAHUN 2014
}

\author{
Binsar M. P. ${ }^{1}$, Syahril Gultom ${ }^{2}$, Tulus B. Sitorus ${ }^{3}$, Farel H. Napitupulu ${ }^{4}$, Terang UHS Ginting ${ }^{5}$ \\ 1,2,3,4,5 Departemen Teknik Mesin, Fakultas Teknik, Universitas Sumatera Utara \\ Email: binsarsteven@ymail.com
}

\begin{abstract}
ABSTRAK
Kesempurnaan pembakaran yang diindikasikan dengan rendahnya emisi gas buang yang dihasilkan serta penurunan konsumsi bahan bakar pada Mesin Diesel, terus menerus dikembangkan dan dilakukan penelitian. Begitu pula penggunaan magnet untuk memperbaiki karakteristik muatan listrik campuran bahan bakar dan udara agar didapat campuran yang homogen, hal ini terus menerus dikembangkan dan diteliti. Pada penelitian ini dilakukan pada mobil Pajero Sport Dakar Diesel dengan menggunakan alat magnetasi bahan bakar. Kuat medan magnet yang berbeda-beda, penempatan posisi alat magnetasi pada fuel line, variasi putaran 1000 sampai $3000 \mathrm{rpm}$ dengan mesin konstan. Dari hasil pengujian dan perhitungan yang telah dilakukan didapat bahwa penggunaan magnetasi dapat menurunkan konsumsi bahan bakar sampai dengan $26 \%$ dan meningkatkan efisiensi thermal sampai dengan $4,5 \%$. Demikian juga pengamatan terhadap emisi gas buang yang dihasilkan menunjukkan penurunan opasitas yang lebih rendah dari pada tidak menggunakan magnetasi.
\end{abstract}

Kata Kunci : Magnetasi Bahan bakar, meningkatkan efisiensi dan menurunkan Opasitas.

\section{PENDAHULUAN}

Bahan bakar merupakan salah satu sumber energi yang tidak dapat diperbaharui, sedangkan pada penggunaannya semakin hari semakin meningkat seiring dengan laju pertumbuhan penduduk dan aktifitas manusia, sehingga persediaan bahan bakar terus berkurang.

Bahan bakar yang biasa digunakan pada industri maupun rumah tangga biasanya bahan bakar minyak. Bahan bakar minyak adalah bahan bakar yang pada suhu kamar berfase cair. Bahan bakar ini menghasilkan panas yang lebih tinggi jika dibandingkan dengan bahan bakar batu bara.

Pada dunia otomotif, bahan bakar merupakan salah satu kebutuhan primer yang membuat mesin dapat bekerja secara maksimal. Oleh karena itu manusia harus berusaha untuk menekan pemakaian bahan bakar dengan cara melakukan penghematan agar kelangsungan penggunaan mesin-mesin otomotif dapat terjaga.

Salah satu cara melakukan penghematan bahan bakar yaitu dengan meningkatkan efisiensi bahan bakar. Peningkatan efisiensi bahan bakar dapat terjadi apabila suatu medan magnet yang kuat diaplikasikan kesaluran bahan bakar motor diesel. Efisiensi pembakaran yang dihasilkan dapat secara signifikan meningkat pada kondisi-kondisi tertentu.

Ide untuk melakukan magnetasi bahan bakar hidrokarbon dapat meningkatkan pembakaran dan efisiensi motor sudah ada sejak akhir tahun 1930-an. Hasil yang didapat menunjukan adanya peningkatan 15\% untuk suatu jarak tempuh. Magnetasi bahan bakar ini memerlukan penggunaan magnet yang berukuran besar yang sebanding dengan kekuatan medan magnetnya. Akhir-akhir ini ide tersebut dikembangkan kembali dengan mempertimbangkan adanya komposisi material baru yang memiliki kekuatan magnet yang tinggi dan juga lebih ringan.

Saat ini dipasaran lokal sudah beredar bermacam-macam magnet yang diklaim mampu meningkatkan efisiensi pembakaran secara signifikan. Tetapi sejauh ini magnet 
yang diproduksi dan dijual dipasaran adalah magnet dipole ( kutub yang sama $U$ - S ). Sementara itu, secara tidak disadari fenomena magnet monopole ( kutub yang berlawanan $\mathrm{S}-\mathrm{S}$ ) yang sebetulnya lebih dahulu muncul, namun perkembangannya kurang mendapatkan perhatian [1].

Karena banyaknya fenomena-fenomena yang diberikan diatas perlu diadakan suatu penelitian yang akan menguji dan menganalisa pengaruh medan magnet pada saluran bahan bakar (fuel magnetizer) dari beberapa produk yang sudah ada di indonesia, khususnya diaplikasikan pada Mobil Pajero Sport Dakar Diesel Tahun 2014.

\section{TINJAUAN PUSTAKA Pengertian Mesin Diesel}

Mesin diesel adalah salah satu tipe dari mesin pembakaran dalam (Intenal Combution engine) yang panasnya dihasilkan dari pembakaran bahan bakar oleh udara bertekanan. Karakteristik dari mesin diesel yang membedakan dari motor bakar yang lain terletak pada metode penyalaannya dan bahan bakarnya. Dalam mesin diesel bahan bakar diinjeksikan keladam ruang bakar yang berisi udara yang bertekanan tinggi. Selama proses pengkompresian udara dalam silinder mesin, suhu udara meningkat, sehingga bahan bakar tersebut berbentuk halus bersinggungan dengan udara panas ini, maka bahan bakar akan menyala dengan sendirinya tanpa bantuan alat penyala lainnya.

Mesin diesel memiliki perbandingan kompresi sekitar $15: 1$ samapi $26: 1$, jauh lebih tinggi dibanding mesin bakar bensin yang hanya berkisar $9: 1$ sampai $15: 1$. Komsumsi bahan bakar spesifik mesin diesel lebih rendah (kira-kira 25\%) dibanding mesin bensin namun perbandingan kompresi yang lebih tinggi menjadikan tekanan kerjanya juga tinggi. [2]

\section{Proses Terbentuknya Bahan Bakar}

Minyak bumi dipanaskan menjadi uap minyak. Uap tersebut didinginkan sehingga terjadi cairan minyak. Pemisahan Solar, ADO, IDO, dan lain-lain, karena terjadi perbedaan titik didih. Minyak bumi yang lebih dulu menguap adalah minyak bumi dengan titik didih rendah. (Seperti pada gambar 1)

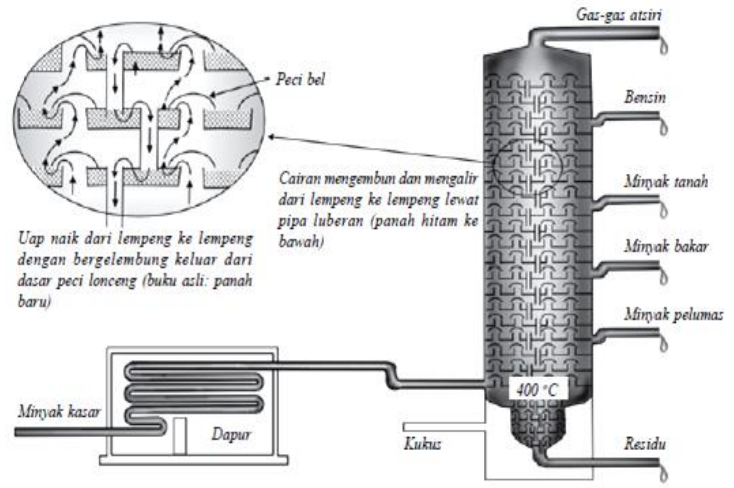

Gambar 1. Proses Penyulingan Minyak (:http://www.penyulinganminyak.com)

Minyak bumi berasal dari plankton-plankton yang tertimbun dalam jutaan tahun. Timbunan dengan tekanan tinggi dan suhu cukup. Plankton-plankton mulu-mula tertimbun dengan pasir didasar laut/air yang tenang. Dekomposisi (pembusukan) yang lambat merubah plankton dengan saprofil (bahan organik yang amorphous). Dekomposisi ini berlangsung selama jutaan tahun.

Plankton yang terdekomposisi ini kemudian timbul dengan berlapis-lapis material dengan $\mathrm{P}$ tinggi dan $\mathrm{T}$ menengah sehingga menghasilkan minyak bumi. Komposisi minyak bumi tergantung pada umur penimbunan. Makin tua umur minyak 
bumi, maka komposisi hidrokarbon ringannya makin tinggi. Minyak bumi yang umur timbunannya tua misalnya minyak bumi timur tengah.

Lapisan penimbunan plankton (deposit) mula-mula menjadi batuan tempat pembentukkan minyak disebut batuan super (source rock). Minyak yang terbentuk lalu berpindah dari batuan yang padat kebatuan yang berpori dan permeable yang terbentuk dari batuan sendiment yang kasar. Batuan yang berpori ini disebut batuan reservoir. Migrasi minyak terjadi sampai bertemu dengan batuan yang tidak dapat dialiri (barrier rock). Cadangan minyak dapat ditemukan pada lokasi yang dibatasi dengan batuan penghalang ini. Batuan penghalang ini juga kenal sebagai batuan penutup (cup rock). Kombinasi batuan sediment dan batuan penghalang membentuk tiap kantong minyak.

\section{Bahan Bakar hidrokarbon}

Setiap material yang dapat terbakar untuk melepaskan energi disebut bahan bakar. Bahan bakar yang umumnya digunakan pada sistem pembakaran terbuka (external combution), seperti kerosine, dan solar, tersusun dalam hidrokarbon yang berbe-beda, yang diperoleh dengan proses penyulingan minyak bumi atau minyak mentah.

Alasan utama mengapa bahan bakar digolongkan sebagai bahan bakar hidrokarbon disebabkan karena komponen utama yang menyusunnya didominasi oleh unsur hidrogen dan unsur karbon(umunya 86\%wt karbon dan 14\%wt hidrokarbon), disamping unsur lainnya yang sangat kecil jumlahnya dan dapat diabaikan.

Namun demikian bahan bakar hidrokarbon dipertimbangkan sebagai hidrokarbon tunggal saja, agar memudahkan dalam mempelajari serta dalam pemakaiannya. Contohnya adalah bensin yang dipertimbangkan oktana, $\mathrm{C}_{8} \mathrm{H}_{18}$ atau solar sebagai dodekana $\mathrm{C}_{12} \mathrm{H}_{26}$.

Bahan bakar lain yang digolongkan kedalam bahan bakar hidrokarbon cair diantaranya metil alkohol $\mathrm{CH}_{3} \mathrm{OH}$, yang disebut metanol. Contoh lain bahan bakar hidrokarbon yang bersifat gas alam, meskipun tersusun dari campuran antara metana dengan sejumlah gas lain, namun untuk kemudahannya cukup disebut metana, $\mathrm{CH}_{4}$.

\section{Minyak Solar}

Minyak solar adalah suatu produk destilasi minyak bumi yang khusus digunakan untuk bahan bakar mesin Compretion Ignation (udara yang dikompresi menimbulkan tekanan dan panas yang tinggi sehingga membakar solar yang disemprotkan Injector) dan di indonesia minyak solar ditetapkan dalam peraturan Dirjend Migas No. 002/P/DM/MIGAS/2007.

Minyak solar berasal dari Gasoil, yang merupakan fraksi minyak bumi dengan kisaran titik didih antara $250^{\circ} \mathrm{C}$ sampai $350^{\circ} \mathrm{C}$ yang disebut juga midle destilat. Komposisinya terdiri dari senyawa hidrokarbon dan non-hidrokarbon. Senyawa hidrokarbon yang ditemukan dalam minyak solar seperti parafinik, naftenik, olepin dan aromatik. Sedangkan untuk senyawa non-hidrokarbon terdiri dari senyawa yang mengandung unsur-unsur non-logam, yaitu sulfur, nitrogen, dan oksigen serta unsur logam seperti vanadium, nikel, dan besi [3.].

\section{Efek Magnetisasi pada Bahan Bakar Diesel}

Adanya medan magnet statis yang besar, awan elektron mengelilingi molekul, sehingga molekul bersifat terpolarisasi dan memberikan kenaikan pada medan yang kecil. Posisi inti atom, pada medan yang sesungguhnya tidak hanya tergantung sekitarnya, akan tetapi sekeliling molekul sendiri. Pada keadaan cair, reorientasi molekul terjadi secara acak. 
Jika atom yang diletakkan dalam medan magnet yang seragam, elektron yang mengelilingi inti menjadi berputar. Perputaran ini menyebabkan medan magnet sekunder yang arahnya berlawanan dengan arah medan magnet yang diberikan.

Ketika solar masih berada dalam suatu penyimpanan bahan bakar, molekul hidrokarbon, yang merupakan penyusun utama solar, cenderung untuk saling tertarik satu sama lain, membentuk molekul-molekul yang bergerombol (clustering). Penggumpalan ini akan terus berlangsung, sehingga menyebabkan molekul-molekul hidrokarbon tidak saling berpisah pada saat bereaksi dengan oksigen diruang bakar. Akibat buruk yang ditimbulkannya adalah ketidak sempurnaan pembakaran yang dapat dibuktikan secara sederhana dengan ditemuinya kandungan hidokarbon pada gas buang.

Adanya suatu medan magnet permanen yang cukup kuat pada melekul hidrokarbon yang bersifat diamagnetik akan menyebabkan reaksi penolakan antar molekul hidrokarbon (desclustering) sehingga terbentuk jarak yang optimal antar molekul hidrokarbon.

Partikel-partikel atom yang membentuk molekul hidrokarbon tersebut akan terpengaruh oleh medan magnet yang ditimbulkan sehingga akhirnya akan menjadi semakin aktif dan arahnya akan terjajar (reorientasi) sesuai dengan arah medan magnet. Aktifitas molekular yang meningkat akibat medan magnet akan menyebabkan pengumpulan molekular terpecah. Oksigen akan lebih mudah bereaksi dengan masingmasing molekul hidrokarbon yang tidak lagi berada dalam gumpalan, sehingga menghasilkan pembakaran yang lebih sempurna dan penurunan kadar emisi gas buang. (Seperti pada gambar 2.)

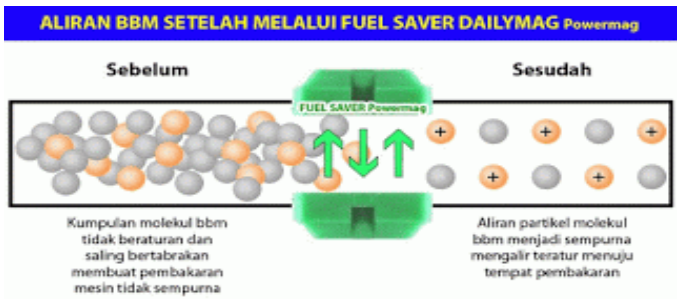

Gambar 2. Declustering molekul hidrokarbon yang melewati magnet (:http://www.bahanbakarsolarmelewatimagnetcom)

Pemecah gumpalan-gumpalan (desclustering) molekul hidrokarbon ini dapat dijelaskan juga melalui teori mengenai momen ikatan. Sebagai contoh, apabila ikatan polar seperti $\mathrm{O}-\mathrm{H}$ dibiarkan dalam medan magnet, maka ikatan akan mengalami sejumlah gaya balik tertentu. Gaya ini secara sederhana mendorong medan magnet untuk membebaskan ikatan dalam medan. Ikatan yang lebih polar mengalami gaya lebih besar daripada ikatan yang kurang polar. H-C termasuk ikatan non-polar, karena nilai momen ikatannya hanya sebesar 0,4 D (Debye). Namun medan magnet yang kuat dapat mengganggu dan mempengaruhi ikatan $\mathrm{H}-\mathrm{C}$. Meskipun ikatan antara atom $\mathrm{H}-\mathrm{C}$ tidak sampai terlepas satu sama lain, namun setidaknya kekuatan ikatannya akan sedikit melemah, sehingga atom-atom hidrogen dan karbon akan lebih mudah tertarik dengan oksigen pada proses pembakaran [4].

\section{Rumus-rumus yang digunakan}

Adapun rumus-rumus yang digunakan adalah sebagai berikut :

1. Torsi dan daya $(\mathrm{Nm})$ dapat dihitung dengan rumus :

$P_{B}=\frac{2 \pi \pi \cdot n}{60} \cdot \mathrm{T}(\mathrm{Nm})[5]$ 
2. Konsumsi bahan bakar spesifik (Sfc) dapat dihitung dengan rumus :

$S f c=\frac{m f \cdot 10^{3}}{P_{B}}(\mathrm{~g} / \mathrm{kWh})[5]$

Dimana :

$m f=\frac{\operatorname{sg}_{f \cdot V_{f} \cdot 10^{-3}}}{t_{f}} 3600(\mathrm{~kg} / \mathrm{h})[5]$

3. Efisiensi volumetris (\%) dapat dihitung dengan rumus :

$\eta_{\mathrm{v}}=\frac{2 . m_{a}}{60 \cdot n} \times \frac{1}{\rho a \cdot V l} \quad(\%)[5]$

4. Efisiensi thermal brake (\%) dapat dihitung dengan rumus :

$\eta_{\mathrm{b}}=\frac{P_{B}}{Q f} \cdot 100 \% \quad$ (\%) [6]

dimana :

$Q_{f}=\frac{C V \cdot m_{f} \cdot 4,184}{3600}(k W)$

\section{METODOLOGI PENELITIAN Metodologi Pengujian}

Pengujian dilakukan untuk mengetahui fenomena yang terjadi pada motor diesel dengan adanya pemasangat magnet pada saluran bahan bakar sebelum Injection Pump. Parameter utama yang diamati yaitu : laju aliran bahan bakar, analisa gas buang yang dihasilkan, dan dilanjutkan dengan menghitung karakteristik performansi dari motor diesel. Pengujian eksperimental ini didasarkan pada kondisi sebagai berikut, yaitu :

$\checkmark$ Tekanan udara luar pada keadaan standar (1 atmosfir);

$\checkmark$ Temperatur ambient dijaga antara $30^{\circ} \mathrm{C}\left(303^{\circ} \mathrm{K}\right)$ sampai $38^{\circ} \mathrm{C}\left(311^{0} \mathrm{~K}\right)$;

$\checkmark$ Aliran solar yang diamati setiap $100 \mathrm{~mL}$;

$\checkmark$ Solar yang digunakan bermassa jenis $0,87 \mathrm{~kg} / \mathrm{L}$;

$\checkmark$ Volume langkah torak, Spesifikasi Mesin : 2475,6544 x $10^{-6} \mathrm{~m} .1$

Dalam pengujian ini diberikan beberapa batasan yang membatasi kebenaran data pengujian, antara lain :

$>$ Kesalahan dalam pembacaan data.

Tingkat ketelitian alat-alat pengujian yang digunakan.

Metode berbagai asumsi untuk memudahkan perhitungan.

Kondisi peralatan dianggap sama untuk setiap kali percobaan.

Solar yang digunakan dianggap sama, dibeli pada satu tempat.

\section{Variasi Pengujian}

Pengujian dilakukan dalam berbagai variasi, agar analisa akhir yang didapatkan dapat memberikan gambaran secara tepat dan signifikan sejauh mana pengaruh pemasangan magnet pada saluran bahan bakar. Variasi pengujian yang dilakukan meliputi :

a. Variasi Merk dan posisi penempatan diselang bahan bakar.

Untuk pengujian kali ini, digunakan 2 buah magnet yang sama. Merk-merk yang digunakan, yaitu : 


\section{Merk = Alindo}

Deskripsi alat :

- Produksi Indonesia;

- Model clip-on;

- Kekuatan Gauss : 2500 dengan jarak antara kutub $\pm 0,75 \mathrm{~cm}$.

Magnet merk Alindo ini adalah magnet dipol yang arah gaya magnetnya kutub utara dah kutub selatan. Penggunaan magnet merk Alindo pada pengujian ini adalah langkah yang tepat, dimana magnet merk Alindo ini mempunyai gauss yang terbesar dari semua magnet yang dipasarkan di indonesia.

b. Variasi Penempatan

Variasi penempatan magnet pada saluran bahan bakar dibagi kedalam 3 variasi posisi penempatan, yaitu :

Tabel 1. Variasi penempatan magnet

\begin{tabular}{|c|c|c|}
\hline Posisi & $\begin{array}{l}\text { Letaknya pada } \\
\text { saluran bahan } \\
\text { bakar }\end{array}$ & Keterangan \\
\hline$X$ & $\begin{array}{lr}\text { Dekat injetion } \\
\text { pump, jarak antara } \\
\text { magnet (1) dan } \\
\text { magnet } \\
\text { berjarak } 2 \mathrm{~cm}\end{array}$ & $\begin{array}{l}5 \mathrm{~cm} \text { dari } \\
\text { injection } \\
\text { Pump }\end{array}$ \\
\hline$Y$ & $\begin{array}{l}\text { Magnet (1) dekat } \\
\text { fuel injection } \\
\text { pump, jarak antara } \\
\text { magnet (1) dan } \\
\text { magnet } \\
\text { berjarak } 10 \mathrm{~cm}\end{array}$ & $\begin{array}{l}\text { Diantara } \\
\text { penempatan } \\
\text { kedua posisi } \\
\text { magnet } \mathrm{X} \\
\text { dan Z }\end{array}$ \\
\hline $\mathrm{Z}$ & $\begin{array}{l}\text { Magnet (2) dekat } \\
\text { dengan fuel filter, }\end{array}$ & $\begin{array}{l}5 \mathrm{~cm} \text { dari } \\
\text { fuel filter }\end{array}$ \\
\hline
\end{tabular}

c. Variasi putaran mesin terhadap pembebanan konstan.

Putaran mesin diatur dalam beberapa variasi putaran, yaitu : 1000, 1500, 2000, 2500, dan $3000 \mathrm{rpm}$.

\section{Pengamatan dan Tahap Pengujian}

1. Parameter Torsi (Nm) dan parameter daya efektif $(\mathrm{Pe})$;

2. Parameter konsumsi bahan bakar spesifik (sfc);

3. Ratio perbandingan udara dan bahan bakar (AFR);

4. Efesiensi volumetric $\left(\eta_{\mathrm{v}}\right)$;

5. Efisiensi thermal efektif $\left(\eta_{e}\right)$;

6. Parameter komposisi gas buang.

Prosedur pengujian dapat dibagi beberapa tahap, yaitu ;

a. Pengujian nilai kalor bahan bakar;

b. Pengujian Mesin diesel dengan bahan bakar solar;

c. Pengujian motor diesel dilakukan dengan memposisikan tiga posisi magnet penghemat bahan bakar. 


\section{Pengujian Performansi Mobil Pajero Sport Dakar}

a. Pengujian sebelum menggunakan magnetasi

Sebelum melakukan pengujian periksa sistem pendingin dan pelumasan apakah bekerja dengan baik dan posisikan mobil pada tempat yang rata, kemudian persiapkan semua peralatan uji yang hendak digunakan, kemudian lakukan pengujian sebagai berikut :

1. Panaskan Mobil sampai suhu kerja mesin;

2. Kemudian hubungkan kabel alat uji Scaning Tool pada soket yang disediakan pada setiap mobil yang menggunakan komputer;

3. Hidupkan Scaning Tool dengan menekan tombol power;

4. Setting alat pada engine control,;

5. Kemudian pilih perintah di Scaning Tool sesuai apa yang hendak kita uji, secara otomatis hasil pengujian akan timbul di layar Scaning Tool;

6. Naikkan putaran (rpm) mesin sampai $1000 \mathrm{rpm}$, dengan menekan pedan gas mobil tersebut;

7. Catat semua hasil pengukuran yang terdapat dilayar scaning tool dan pada tabel pada Dyno Test yang disediakan;

8. Kemudian naikkan putaran mesin pada rpm 1500 lalu catat hasil yang dikeluarkan alat tersebut;

9. Lakukan proses pengujian seperti diatas untuk putaran 2000, 2500, sampai 3000.

b. Pengujian dengan menggunakan magnetasi

Setelah pengambilan data selesai dilakukan pada sebelum menggunakan magnet, kemudian yang kedua menggunakan magnetasi dengan memposisikan magnet yang berbeda-beda.

\section{HASIL DAN ANALISA PENGUJIAN}

\section{Pengujian Performansi Mesin Pajero Sport Dakar}

Data yang diperoleh dari hasil pengujian dan olahan data, antara lain :

- Daya $(\mathrm{kW})$,

- Konsumsi bahan bakar spesifik (Sfc),

- Efisiensi volumetris (\%),

- Efisiensi thermal brake (\%),

- Kadar gas buang (Opasitas)

Data hasil pengujian yang diperoleh untuk berbagai posisi magnet, pada tiap variasi beban dan putaran dapat dilihat pada tabel berikut ini :

\section{Daya}

Berdasarkan daya yang dihasilkan tanpa menggunakan magnet dan menggunakan magnet dengan berbagai posisi pada tiap kondisi dan putaran mesin didapat seperti pada tabel 2 berikut ini.

Tabel 2. Data hasil perhitungan Daya (kW).

\begin{tabular}{|l|c|l|c|c|c|}
\hline No. & $\begin{array}{c}\text { Putaran } \\
\text { mesin (rpm) }\end{array}$ & $\begin{array}{c}\text { Tanpa } \\
\text { magnet }\end{array}$ & $\begin{array}{c}\text { Dengan } \\
\text { magnet Posisi } \\
\mathbf{X}\end{array}$ & $\begin{array}{c}\text { Dengan } \\
\text { magnet } \\
\text { Posisi Y }\end{array}$ & $\begin{array}{c}\text { Dengan } \\
\text { magnet } \\
\text { Posisi Z }\end{array}$ \\
\hline 1. & $\mathbf{1 0 0 0}$ & 7,850 & 8,896 & 8,635 & 8,478 \\
\hline
\end{tabular}




\begin{tabular}{|l|l|l|l|l|l|}
\hline 2. & $\mathbf{1 5 0 0}$ & 15,072 & 16,328 & 15,7 & 15,386 \\
\hline 3. & $\mathbf{2 0 0 0}$ & 30,981 & 31,768 & 31,35 & 31,141 \\
\hline 4. & $\mathbf{2 5 0 0}$ & 54,81 & 56,258 & 55,854 & 55,593 \\
\hline 5. & $\mathbf{3 0 0 0}$ & 81,012 & 83,21 & 81,95 & 81,64 \\
\hline
\end{tabular}

Berdasarkan hasil perhitungan daya maka didapat, seperti pada (tabel 2), daya terendah mesin terjadi pada pengujian dengan tanpa menggunakan magnet pada putaran mesin $1000 \mathrm{rpm}$ yaitu sebesar 7,850 kW. Sedangkan daya tertinggi terjadi pada pengujian dengan menggunakan magnet dan magnet ke-2 pada posisi $\mathrm{X}$ pada putaran $3000 \mathrm{rpm}$, yaitu dayanya sebesar 83,21 kW.

Besar kecilnya daya mesin bergantung pada besar kecilnya torsi suatu mesin yang didapat. Semakin besar torsi maka daya mesin akan semakin besar, sebaliknya semakin kecil torsi mesin, maka daya mesin akan semakin kecil juga. Daya yang dihasilkan mesin dipengaruhi oleh putaran poros engkol yang terjadi akibat dorongan piston yang dihasilkan karena adanya pembakaran bahan bakar dengan udara. Jika konsumsi bahan bakar dan udara diperbesar maka akan semakin besar pula daya yang dihasilkan mesin. Semakin cepat poros engkol berputar maka akan semakin besar daya yang dihasilkan oleh suatu mesin.

Dengan adanya proses magnetasi bahan bakar, maka pembakaran bahan bakar diruang bakar menjadi lebih sempurna dari pada tanpa menggunakan magnet sama sekali, Pada pengujian ini bertambahnya daya sangat dipengaruhi oleh proses magnetasi bahan bakar, pernyataan ini dapat di yakini dengan data hasil percobaan diatas.

\section{Konsumsi bahan bakar spesifik (Sfc)}

Konsumsi bahan bakar spesifik (Specific Fuel Consumtion) dari masing-masing pengujian dengan tanpa menggunakan magnet dan menggunakan magnet dengan variasi penempatan magnet dan putaran mesin yang berbeda-beda dapat didapat dari hasil

\begin{tabular}{|l|c|c|c|c|c|}
\hline \multirow{2}{*}{ No. } & $\begin{array}{c}\text { Putara } \\
\mathbf{n} \\
\text { mesin } \\
(\mathbf{r p m})\end{array}$ & \multicolumn{4}{|c|}{ Konsumsi bahan bakar spesidik (Sfc) } \\
\cline { 3 - 6 } & & $\begin{array}{c}\text { Tanpa } \\
\text { magnet }\end{array}$ & $\begin{array}{c}\text { Dengan } \\
\text { magnet } \\
\text { Posisi X }\end{array}$ & $\begin{array}{c}\text { Dengan } \\
\text { magnet } \\
\text { Posisi Y }\end{array}$ & $\begin{array}{c}\text { Dengan } \\
\text { magnet } \\
\text { Posisi Z }\end{array}$ \\
\hline 1. & $\mathbf{1 0 0 0}$ & 275,159 & 203,462 & 213,317 & 219,863 \\
\hline 2. & $\mathbf{1 5 0 0}$ & 197,850 & 147,545 & 156,433 & 162,16 \\
\hline 3. & $\mathbf{2 0 0 0}$ & 146,516 & 113,321 & 124,880 & 128,943 \\
\hline 4. & $\mathbf{2 5 0 0}$ & 121,565 & 105,041 & 112,149 & 117,37 \\
\hline 5. & $\mathbf{3 0 0 0}$ & 115,402 & 104,555 & 109,188 & 112,824 \\
\hline
\end{tabular}
perhitungan. (Seperti pada tabel 3) berikut ini :

Tabel 3. Data hasil perhitungan Sfc $(\mathrm{g} / \mathrm{kWh})$ Berdasarkan hasil perhitungan Sfc maka didapat, Sfc terendah terjadi pada pengujian dengan menggunakan magnet dan magnet ke-2 pada posisi X pada putaran mesin $3000 \mathrm{rpm}$ yaitu sebesar 104,555 g/kWh. Sedangkan Sfc tertinggi terjadi pada pengujian tanpa menggunakan magnet pada putaran mesin $1000 \mathrm{rpm}$ yaitu sebesar $275,159 \mathrm{~g} / \mathrm{kWh}$.

Besarnya Sfc sangat dipengaruhi oleh waktu untuk mengkonsumsi bahan bakar yang telah ditetapkan dan besar kecilnya daya yang dihasilkan oleh mesin itu sendiri. Menurunnya Sfc pada pengujian ini dipengaruhi oleh besarnya daya yang dihasilkan mesin itu sendiri pada putaran tertentu.

Adanya kecenderungan peningkatan Sfc dengan kenaikan putaran mesin pada beban konstan disebabkan oleh waktu priode persiapan pembakaran yang pendek, sehingga pencampuran bahan bakar dengan udara tidak berlangsung dengan baik. 


\section{Efisiensi volumetris (\%)}

Efisiensi volumetris (volumetric efficiency) untuk motor bakar 4 tak/langkah didapat dari hasil perhitungan. (Seperti pada tabel 4) berikut ini :

Tabel 4. Data hasil perhitungan Efisiensi volumertris (\%)

Berdasarkan

perhitungan efisiensi

volumetris maka

didapat,

pengujian tanpa

menggunakan magnet

dan menggunakan

magnet dengan

berbagai posisi magnet,

Efisiensi volumetris

tertinggi terjadi pada

semua pengujian

menggunakan magnet

\begin{tabular}{|c|l|c|c|c|c|}
\hline \multirow{2}{*}{ No. } & Putara & \multicolumn{4}{|c|}{ Efisiensi volumetris (\%) } \\
\cline { 3 - 6 } & $\begin{array}{l}\text { mesin } \\
(\mathbf{r p m})\end{array}$ & $\begin{array}{c}\text { Tanpa } \\
\text { magnet }\end{array}$ & $\begin{array}{c}\text { Dengan } \\
\text { magnet } \\
\text { Posisi X }\end{array}$ & $\begin{array}{c}\text { Dengan } \\
\text { magnet } \\
\text { Posisi Y }\end{array}$ & $\begin{array}{c}\text { Dengan } \\
\text { magnet } \\
\text { Posisi Z }\end{array}$ \\
\hline 1. & $\mathbf{1 0 0 0}$ & 68,41 & 69,04 & 68,79 & 68,66 \\
\hline 2. & $\mathbf{1 5 0 0}$ & 73,3 & 73,65 & 73,48 & 73,39 \\
\hline 3. & $\mathbf{2 0 0 0}$ & 84,73 & 84,73 & 84,73 & 84,73 \\
\hline 4. & $\mathbf{2 5 0 0}$ & 85,36 & 85,36 & 85,36 & 85,36 \\
\hline 5. & $\mathbf{3 0 0 0}$ & 92,062 & 92,062 & 92,062 & 92,062 \\
\hline
\end{tabular}

dan tidak menggunakan magnet pada putaran $3000 \mathrm{rpm}$ dengan efisiensi 92,062\%. Sedangkan Efisiensi volumetris terendah terjadi pada pengujian tanpa menggunakan magnet dengan putaran $1000 \mathrm{rpm}$ dengan efisiensi volumetris $68,41 \%$.

Efisiensi volumetris menunjukkan perbandingan antara jumlah udara yang terhisap sebenarnya terhadap jumlah udara yang terhisap sebanyak volume langkah torak untuk setiap langkah isap. Efisiensi volumetris sangat dipengaruhi oleh putaran mesin, semakin tinggi putaran mesin maka efisiensi volumetris akan semaikn besar dan sebaliknya, semakin rendah putaran mesin maka efisiensi volumetris akan semakin kecil.

\section{Efisiensi thermal brake (\%)}

Efisiensi thermal brake (Brake thermal efficiency) merupakan perbandingan antara daya keluaran aktual terhadap laju panas rata-rata yang dihasilkan dari pembakaran bahan bakar, didapat dari hasil perhitungan. Seperti pada tabel berikut ini :

Tabel 5. Data hasil perhitungan Efisiensi thermal brake (\%)

\begin{tabular}{|c|c|c|c|c|c|}
\hline \multirow{2}{*}{ No. } & Putaran & \multicolumn{4}{|c|}{ Efisiensi thermal brake (\%) } \\
\cline { 3 - 6 } & \multirow{2}{*}{} & & \multicolumn{4}{|c|}{} \\
\cline { 3 - 6 } & & $\begin{array}{c}\text { Tanpa } \\
\text { magnet }\end{array}$ & $\begin{array}{c}\text { Dengan } \\
\text { magnet Posisi } \\
\mathbf{X}\end{array}$ & $\begin{array}{c}\text { Dengan } \\
\text { magnet Posisi } \\
\mathbf{Y}\end{array}$ & $\begin{array}{c}\text { Dengan } \\
\text { magnet Posisi } \\
\mathbf{Z}\end{array}$ \\
\hline 1. & $\mathbf{1 0 0 0}$ & 8,51 & 11,06 & 10,55 & 10,24 \\
\hline 2. & $\mathbf{1 5 0 0}$ & 11,38 & 15,26 & 14,39 & 13,88 \\
\hline 3. & $\mathbf{2 0 0 0}$ & 15,37 & 19,9 & 18,06 & 17,49 \\
\hline 4. & $\mathbf{2 5 0 0}$ & 18,56 & 21,44 & 20,12 & 19,23 \\
\hline 5. & $\mathbf{3 0 0 0}$ & 19,51 & 21,53 & 20,62 & 19,95 \\
\hline
\end{tabular}

Berdasarkan hasil perhitungan efisiensi thermal brake maka didapat, pada pengujian tanpa menggunakan magnet dan menggunakan magnet dengan berbagai posisi magnet, Efisiensi thermal brake terendah terjadi pada pengujian dengan 
pengujian tanpa menggunakan magnet pada putaran $1000 \mathrm{rpm}$, dengan efisiensi thermal brake sebesar $8,51 \%$. Sedangkan efisiensi thermal brake tertinggi terjadi pada pengujian dengan menggunakan magnet pada posisi X pada putaran $3000 \mathrm{rpm}$ dengan efisiensi thermal brake sebesar $21,53 \%$.

Efisiensi thermal brake dari bahan bakar sangat dipengaruhi oleh terjadinya pembakaran bahan bakar diruang bakar yang lebih sempurna. Meningkatnya efisiensi thermal brake ini sangat dipengaruhi oleh magnetasi bahan bakar pada pengujian kali ini. Dimana efisiensi thermal brake dapat meningkat hingga 4,53\% (seperti pada tabel 4.15 dengan putaran $2000 \mathrm{rpm}$ dengan magnet posisi X) dari efisiensi thermal brake sebelum menggunakan magnetasi bahan bakar.

\section{Emisi gas buang/Opasitas (\%)}

Pengujian ini, data yang diperoleh dari beberapa pengujian baik tanpa menggunakan magnet maupun menggunakan magnet dengan berbagai putaran mesin, harga Opasitas dapat dilihat pada tabel. 6. berikut ini :

Tabel 6 . Data hasil pengujian emisi gas buang/Opasitas (\%)

\begin{tabular}{|c|c|c|c|c|c|c|}
\hline \multirow{3}{*}{\begin{tabular}{l}
\multicolumn{2}{c}{ Pada } \\
pengujian kadar \\
gas buang ini \\
hanya nilai \\
opasitasnya vang
\end{tabular}} & & & & & & \\
\hline & \multirow{2}{*}{ No. } & \multirow{2}{*}{$\begin{array}{c}\text { Putaran mesin } \\
\text { (rpm) }\end{array}$} & \multicolumn{4}{|c|}{ Kadar gas buang (Opasitas/CO) $\{\%\}$} \\
\hline & & & $\begin{array}{c}\text { Tanpa } \\
\text { magnet }\end{array}$ & $\begin{array}{l}\text { Dengan } \\
\text { Magnet } \\
\text { Posisi X }\end{array}$ & $\begin{array}{l}\text { Dengan } \\
\text { Magnet } \\
\text { Posisi Y }\end{array}$ & $\begin{array}{l}\text { Dengan } \\
\text { magnet } \\
\text { Posisi Z }\end{array}$ \\
\hline diuji, dimana & 1. & 1000 & 4,6 & 2,1 & 3,3 & 4,5 \\
\hline lai untuk setiap & 2. & 1500 & 5,2 & 3,2 & 4,2 & 4,6 \\
\hline & 3. & 2000 & 6,2 & 4,2 & 4,3 & 4,8 \\
\hline gnet dan tanpa & 4. & 2500 & 13,3 & 6,8 & 8,4 & 8,5 \\
\hline gnet telah & 5. & 3000 & 14,9 & 9,6 & 10,6 & 10,6 \\
\hline
\end{tabular}

diuraikan pada tabel 4.17 diatas. Adapun nilai opasitas dari semua pengujian yang paling rendah terdapat pada pengujian dengan menggunakan magnet pada posisi X pada putaran $1000 \mathrm{rpm}$ dengan nilai opasitasnya 2,1\%. Dan nilai opasitas yang paling tinggi terdapat pada pengujian tanpa menggunakan magnet pada putaran $3000 \mathrm{rpm}$ dengan nilai opasitasnya $14,9 \%$.

Emisi gas buang carbon monoksida (CO) terjadi akibat kekurangan oksigen, sehingga proses pembakaran berlangsung secara tidak sempurna karena banyak atom $\mathrm{C}$ (karbon) yang tidak mendapatkan cukup oksigen. Akibatnya membentuk gas CO. Dengan menggunakan magnetasi bahan bakar pada pengujian ini dapat membantu penyempurnaan proses pembakaran antara campuran udara-bahan bakar didalam silinder karena molekul-molekul bahan bakar yang masuk kedalam ruang bakar dapat terionisasi oleh magnet tersebut.

\section{KESIMPULAN}

Berdasarkan analisa dan pengujian yang telah dilakukan, dapat disimpulkan beberapa hal, antara lain :

1. Magnetasi bahan bakar solar dengan magnet pada saluran bahan bakarnya terbukti memberikan efek pembakaran yang lebih sempurna untuk kondisi mesin yang sama. Hal ini terlihat pada terjadinya penurunan terbesar jumlah bahan bakar solar yang dikonsumsi oleh mesin per HP/jamnya.

2. Pemasangan magnet perlu diperhatikan dengan seksama. Diusahakan kedua sisi berada pada posisi yang sejajar (saling berhadap-hadapan). Jangan sampai salah satu 
sisinya berada dalam posisi yang miring terhadap sisi yang lainnya. Hal ini akan mempengaruhi arah garis gaya magnet yang terjadi diantara keduanya, sementara garis gaya magnet tersebutlah yang mempengaruhi susunan unsur bahan bakar yang lebih teratur.

3. Efek magnetasi bahan bakar yang terbaik adalah dengan meletakkan magnet sedekat mungkin pada injection pump dan meletakkan magnet ke-2 dekat dengan magnet 1 , atau pada posisi x. Dengan pengiritan konsumsi bahan bakar dapat mencapai $26 \%$.

4. Magnetasi bahan bakar yang menyebabkan kenaikan daya output mesin diesel, jika dibandingkan dengan mesin yang tidak menggunakan magnetasi pada saluran bahan bakarnya.

5. Semakin lama penggunaan magnetasi pada saluran bahan bakar mesin diesel makan akan semakin baik peningkatan yang terjadi, hal tersebut dapat dilihat penurunan nilai SFC, peningkatan efisiensi termal, dan penurunan kadar asap gas buang (opasitas).

6. Pengaruh magnetasi bahan bakar mesin diesel dapat terlihat dari penurunan gas asap (opasitas) yang dihasilkan.

\section{SARAN}

Adapun saran-saran yang dapat diajukan pada penggunaan magnetasi bahan bakar ini untuk menyempurnakan pemakayan magnetasi bahan bakar ini antara lain :

1. Untuk mengetahui efek dari penggunaan magnetasi pada saluran bahan bakar, dalam hal ini mesin diesel, sebaiknya dilakukan pemakaian magnetasi dalam jangka waktu yang cukup lama, agar sisa-sisa pembakaran yang tidak sempurna sebelum pemakaian magnet yang terdapat dalam mesin dapat terbuang secara keseluruhan dan hasil yang dicapai dapat lebih optimal.

2. Sebaiknya untuk pengujian efek magnet ini digunakan produk yang asli dengan panjang yang berbeda-beda, sehingga pengaruh dari perpanjangan efek magnet dapat lebih jelas terlihat.

3. Sebaiknya dalam penggunaan magnetasi bahan bakar baik solar maupun bensin, menggunakan dua buah magnet pada saluran bahan bakar agar proses magnetasi bahan bakar lebih sempurna.

\section{DAFTAR PUSTAKA}

[1.] J Arjuna et al 2018 IOP Conf. Ser.: Mater. Sci. Eng. 309012088

[2.] Arismunandar, W, "Motor Bakar Torak," ITB, Bandung, 1983.

[3.] Pertamina, Karakterisasi Minyak

Solar Indonesia dan pembuatannya, Jakarta, 1999.

[4.] Irvan et al 2017 IOP Conf. Ser.: Mater. Sci. Eng. 206012028

[5.] F. Ariani et al 2017 IOP Conf. Ser.: Mater. Sci. Eng. 277012045

[6.] Willard W.Pulkrabek, Engineering

Fundamentals of the Internal Combustion Engine. Upper saddle river, new Jersey. 